\title{
The Research on Reverse Logistics of Electronic Products
}

\author{
Sun Huimin \\ Engineering Training Center \\ Shenyang Aerospace University \\ Shenyang, China \\ Sunhuimin@sau.edu.cn
}

\begin{abstract}
By reverse logistics, we can not only recycle waste materials but also control environmental pollution caused by waste materials effectively, so it has high market value, especially for electronic products, which updates quickly with short price cycle and fierce competition. Besides, pollution by electronic waste is also serious. Due to this, reverse logistics plays an important role in maintaining the assets of electronic product enterprises. However, electronic product enterprise may have some difficulty in implementing reverse logistics, such as inappropriate management and storage control, which will result in bad influences on cost, capital turnover and decrease of credits as well as its sustainable development.
\end{abstract}

Keywords-reverse logistics, electronic products, optimization, internet

\section{INTRODUCTION}

China is a big country with large population. With constant development of economy and people's living standard, consumption has become individualized and diversified. At the same time, consumption of electronic products has increased year by year. In order to appeal to people's consumption concept, electronic product enterprise has been constantly developing new products with a quick update and high mortality rate. Thus mortality rate of waste electronic products has been soaring year by year.

\section{STATUS QUO OF REVERSE LOGISTICS FOR ELECTRONIC PRODUCTS}

However, there are some problems existing in reverse logistics of electronic products. For a long time, recycling of electronic products in our country has been in the lowlevel mode with low efficiency and huge pollution for its small scale and large mortality rate, such as scattered recycling, secondary use, indigenous decomposition, which has gradually received attention and concerns from both people and enterprises.

By reverse logistics of electronic products, we can first raise the utility rate of resources and lower the cost effectively with sound corporation image so as to achieve more market space and economical profits with leading position; besides, we can reduce environmental pollution of electronic products by implementing earnestly laws and regulations about environmental protection and energy conservation in our country.
According to the data released by national development and reform commission, electronic product waste in our country has entered into a peak period with over 50 millions of waste each year theoretically, and the annual increase rate is $20 \%$. It is predicted that the annual waste will reach to 160 millions by the end of " 12 th five-year plan". It'll make serious burden on environment if this huge discard amount can't be timely disposed, and people's trust in enterprise's ethics and morality will be lost. The effect of operation and implementation of reverse logistics by electronic product enterprise will directly influence enterprise's credibility, social image, operational cost, customer's service level as well as customer's evaluation on product quality. However, reverse logistics of electronic products in our country starts late, and electronic product enterprise is facing with huge challenges. Under this development trend, enterprise has to strengthen the operational management of reverse logistics to be more competitive.

\section{OUTLINE OF REVERSE LOGISTICS FOR ELECTRONIC PRODUCTS}

With an increasing demand for electronic products, electronic waste has also increased a lot. Most waste electronic products can't be effectively recycled since reverse logistics of electronic products in our country is still nonstandard. Therefore, there exists huge resource waste and environmental safety risk.

Reverse logistics of electronic products includes two aspects, reprocess and scrap waste electronic products. It can be explained from the objects, purpose and constitution. From the perspective of object, reverse logistics of electronic products means a "reverse" flowing process in which discarding or scraping waste electronic products with supply chain or recycle chain from customers. From the perspective of flowing purpose, reverse logistics aims to regain the utility value of electronic products or deficient electronic products as well as correct disposal of final waste. As for the constitution of logistics activities, it should contain recycling, classification, examination, disassembly, reproduction as well scrap processing of electronic products.

The electronic market in our country has huge development potential. From the long term, it fits the market and social needs to implement reverse logistics by electronic enterprise, which is good to lower the cost and raise customer's satisfaction. Meanwhile competitiveness 
can also be strengthened so that domestic enterprises can better deal with international competition.

\section{THE DEVELOPMENT FEATURES OF REVERSE LOGISTICS FOR ELECTRONIC PRODUCTS}

Reverse logistics in our country has many deficiencies since it starts late. So reverse logistics of electronic products in our country has its own features.

Reverse logistics of electronic products has sociability. Reverse logistics is a social activity which needs common efforts together by enterprises, individuals and government rather than just an enterprise's responsibility. Only if all society work together, we can pull the development of reverse logistics for a better environment.

Reverse logistics of electronic products has uncertainty, or we can call it dispersion. At present, we have no complete reverse logistics system. It is difficult for us to recycle extensively because discarded electronic products are dispersed by different customers, besides we are unsure about the quantity, the place as well as the producing time of electronic wastes.

Reverse logistics of electronic products has complexity The electronic wastes have complex varieties and quantities because they have many brands, varieties and models. Therefore we need very professional selection and disposal of the wastes for their different damaged conditions and complex internal structure with accurately distinguishing which can be recycled and which can not be disposed.

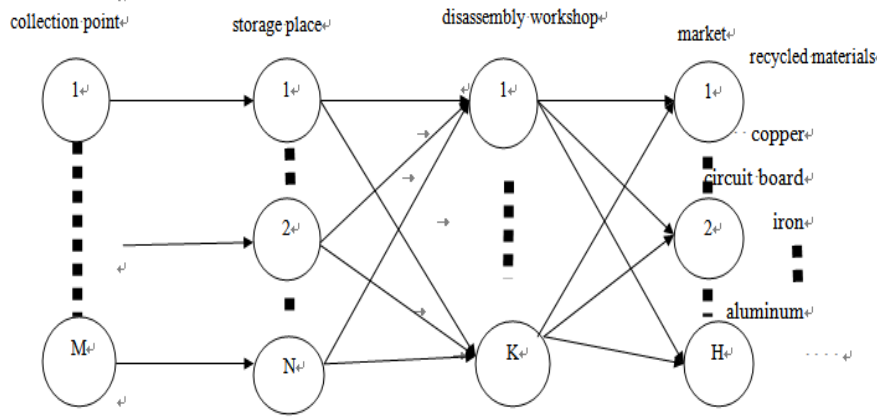

Figure 1. Model of recycling and processing of electronic wastes

Reverse logistics of electronic products has slow economic returns. The recycled electronic wastes can't be used for a long time process. Unlike logistics can have quick increase of value in package, transportation, delivery and storage, reverse logistics has high recycling cost with much investment in early stage since its capital can't be withdrew in the section of waste process. All of these will lead to difficult capital turnover of reverse logistics for its high operational cost, long-period economic returns.

\section{ANALYSIS ON THE PROBLEMS AND REASONS FOR REVERSE LOGISTICS OF ELECTRONIC PRODUCTS}

With the rapid development of electronic industry, most electronic products have entered into a stage of second purchase or even repeat purchase. Reverse logistics is even popular among electronic products for its quick update, high repeat value and huge waste pollution. In addition, the constant decrease of product price is conflict with the increase of cost. Many small electronic products of low quality will have increasingly high reverse logistics rate. Therefore, management of reverse logistics is of vital importance to electronic industry.

Although good management of reverse logistics can bring economic and social benefits for electronic product enterprise, reverse logistics of electronic products starts late with backward technology and deficient management, facing many problems.

- Most recycling enterprises are of small scales with low technology as well as imperfect and ineffective reverse logistics. At present, market of electronic product reverse logistics is very disordered due to the lack of imperfect recycling system. Most electronic wastes are collected by street waste recycling, which is very small of primitive process and backward technology without guaranteeing the quality.

- People and enterprise have less knowledge about the harm of waste electronic products. Although some enterprises have the ability of disposing waste electronics, most enterprises of small size simply disassemble, fire or berry them without recognizing the pollution on environment. Apart from enterprises, people in daily life usually throw away battery freely.

- Lacking perfect legal system and policy to control the recycling and recovery of waste electronic products. Reverse logistics of waste electronics should be led by government and guided by laws. People should be imposed on environmental concept with more promotion so that they can realize the harm of waste electronics on environment. Then enterprises who devote to disposal of waste electronics can have more space for stable development.

- Management of electronics reverse logistics is difficult with many uncertainties and high cost. Products recovered or recycled from customers are totally different without an united standard in terms of quality, quantity, lifespan, extent of damage as well as usage time and environment. Therefore, initiative investment on disposing waste electronics is high but with long-term profit returns, which is bad for capital turnover.

\section{OPTIMIZED STRATEGIES AND SUGGESTIONS TO THE} IMPLEMENTATION OF ELECTRONICS REVERSE LOGISTICS

Addressing the status quo as well as existing problems in the development of electronics reverse logistics, some optimized strategies and suggestions are given as follows.

Strengthen the publicity and increase environmental awareness of people and enterprises. Saving resources and protecting environment should be advocated in the whole society so that all people can understand, support and participate in recovery and recycling actively. Besides, more electronic product enterprises should be encouraged to establish reverse logistics system. Meanwhile, necessity of implementing electronic reverse logistics should be publicized by common and acceptable ways like newspapers, television, broadcast, opusculum and so on.

Establish effective recycling system for reverse logistics. Although the time, place and quantity of reverse logistics are of great uncertainty, efficiency and benefits of reverse logistics have been greatly improved due to the 
current bar code technology, GPS technology, EDI technology and so on. In addition, enterprises on the reverse logistics chain can share information about sales return by the effective recycling system so that all enterprises can check and inquire information whenever they need for a better management of sales return.

Strengthen the role of government in developing reverse logistics. Full play should be given to government's functions of organization, coordination and planning so that it can create sound external environment for the development of reverse logistics by issuing relative laws for a fair, open and ordered market. Meanwhile, some political regulations should be formulated to support the reverse logistics in electronic product enterprise, for example, some preferential policies can be given to enterprises in terms of tax. Besides, some incentive mechanisms can be given to consumers so that they can recycle and recover waste electronics actively for a high recycling rate.

More research and evaluation should be conducted in related fields of electronics reverse logistics by combining technological powers from government, enterprises and scientific institute all together. Strengthen the study on the process of waste electronics for less environmental pollution but greater recycling profit.

Strengthen the cultivation talents who master technology of electronics reverse logistics. Nowadays comprehensive talents for management and technology are of extreme shortage in our country. To develop reverse logistics, domestic electronic product enterprise can build an employee team of comprehensive qualities by planned absorption, improvement and cultivation.

Carry out the responsibility system of manufacturers. The electronic product enterprise knows better about their products' structure, artwork, raw material and so on, so they should ensure the quality so that they can recycle and reuse later for environment protection and cost saving.

Establish information tracking system for electronics reverse logistics. According to the tracking system, we can know the reason for consumer's sales return and make improvement according to the reason so as to ensure an effective and efficient solution. By introducing bar code technology and RFID, we can establish electronic information platform and have timely and dynamic track on products so that detailed information like product's defect and product flow can be better mastered.

Develop reverse logistics by actively learning advanced experience from other countries and combining it with our own domestic conditions. They have many beneficial experience worthy to be learned such as their processing technology. Like Japan and America, they have developed management and processing for our reference, meanwhile we can learn their perfect legal system.

Perfect market competition mechanism. Universal standard on accessories of electronic products should be provided by market to avoid waste of resources as well as overstock of electronic products and accessories. Therefore electronic product enterprises can discipline themselves according to this standard to improve competition awareness and product quality.

Pilot project for reverse logistics of electronic products. Since the reverse logistics of waste electronics in our country is still under the exploration stage without any feasible experience or mode can be learned. So we can do some experiment in some important areas to reduce mistakes. Demonstrative project can be established in demonstrative area. During its operation, development mode beneficial to the development of reverse logistics can be explored and then further popularized in the whole country so as to promote creative development with constant experience summary and resources waste reduction.

In the future, government should guide audience by legislating laws and popularizing recycling logistics system of waste electronics. Also laws regarding recycling of waste electronics should be formulated to make up for the blank. We should implement recycling of waste electronics as a compulsory policy. Meanwhile, electronic manufacturers should be guided to value environmental protection as their social responsibility and duty with preferential policies on tax and loans. As for electronic manufacturers, they should advocate environmental logistics by reducing the harm and release of electronic waste. Meanwhile, during their production, they can produce accessories easy to be disassembled and classified so as to reduce the complexity in recycling. While as for massive consumers, we should increase the awareness of environmental protection by participating in the recycling of waste electronics actively.

\section{CONCLUSION}

Based on relative theories of reverse logistics and enlightened by development of reverse logistics for waste electronics home and abroad, the paper proposed some suggestions to problems of reverse logistics for electronic products.

Although development of electronics reverse logistics still in the theoretical stage or early stage in our country, it will surely bring more benefits for both enterprises and environment in the coming future. Reverse logistics is a major part of economic sustainable development, and electronics reverse logistics has great significance for sustainable development as well as environmental protection. Therefore, as a new source of profit, implementation of reverse logistics for electronic products is imperative which will surely have sound development.

Our government should build an incentive mechanism as soon as possible which is helpful for the establishment of electronics reverse logistics system; meanwhile enterprises should constitute appropriate reverse logistics system adaptable to their own development. By this, electronic industry in our country can receive sustainable development. Since awareness of environment pollution by waste electronics can't be valued by the whole society, our government should strengthen publicity and education so as to push the development of electronics reverse logistics with this awareness.

\section{REFERENCES}

[1] Wang Yining, Analysis on Reverse Logistics of Electronic Products[J].Modern Commercial Industry, 2010(20):28-29.

[2] Luo Zhengqing, Chen Xufang. Research on Contributing Factors As Well As Management and Countermeasures[J].Logistics and Science, 2013(8):8-11.

[3] Zhao Xiurong, Anna, Wangjing, Research on Value Connotation As Well As Implementation Scheme of Reverse Logistics[J], Logistics and Science, 2013(3):148-149. 
[4] Cheng Changsheng, Implementation Obstacles and Measures Selection of Reverse Logistics in E-business[J]. Technological Application, 2010(12) : 142.

[5] Han Qiyun, Gao Linhai, Zhao Jilin, Discussion on Reverse Logistics[J].Logistics and Science, the 110th issue:1-3.

[6] Huangle, Research on the Reasons and Classifications of Reverse Logistics[J]. Review on Social Science.2012(12):48-49.

[7] Pokharel .Mutha Akshay, Perspectives in reverse logistics:A review, Elsevier, P.O. Box 211, Amsterdam, 1000 AE, Netherlands[C].2013(7).

[8] Shi Yujie, Analysis on the Value of Enterprise Reverse Logistics As Well As Implementation Suggestions[J]. Popular Business, 2012(3):31.

[9] Guoqi, Zhao Xiaohui, Yanwei. Analysis on the Development of Electronics Reverse Logistics in Our Country.[J]. Journals in Xi'an Institute of Post and Telecommunications. 2013(3):122-126.
[10] Sun Yingsun, Dingbing, Research Review on Reverse Logistics[C]. Journals in Anhui Business Vocational Technical Institute , 2014 (9) .

[11] Leilei, Quli, Research Review on Reverse Logistics of Waste Electronics[J]. Ecological Economy, 2010 (9) : 141-145.

[12] stock J R. 《Reverse logistics 》 , Council of logistics Management[M].2012 年.

[13] Ahmad Alshamrani.Chandal Nahak. Adaptive Control of a Reverse Logistic Inventory Model with Uncertain Deteriorations and Disposal Rates, [J].Advances in Operations Research .2012 年.

[14] Sun Liangtao, Problems and Countermeasures of Reverse Logistics in E-commerce in Our Country[J]. Technology and Market.2011 (10) : 98-99.

[15] Wang Donghong, Analysis of Value As Well As Research on Strategies of Reverse Logistics for Electronic Products[J]. Logistics and Science 2010 (2) : 34-36. 